\title{
Основные направления и концепции биоморфологии в России
}

\author{
() Н.П. Савиных ${ }^{1}$, В.А.Черёмушкина ${ }^{2}$ \\ ${ }^{1}$ Вятский государственный университет, г. Киров, Россия \\ e-mail: savva_09@mail.ru

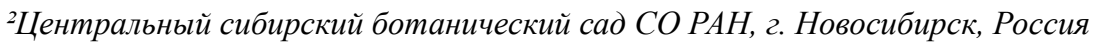 \\ e-mail:cher.51@mail.ru
}

\begin{abstract}
На основе анализа многолетних исследований биоморфологии разных групп растений отмечены основные направления (структурное, онтогенетическое, экологическое, географическое, эволюционное) и основные концепции (системный подход при анализе жизненных форм; представление о растении как модульном организме с меняющимся габитусом в течение всей жизни; фаза морфогенеза как процесс и результат; циклический морфогенез как основа формирования тела растения; двойственность жизненных форм, обусловленная генетически запрограммированной основой формообразования и возникающими на этом фундаменте модификациями) этой современной науки.
\end{abstract}

Ключевые слова: биоморфолоогия, структурная организация, онтоморфогенез, модульная организация, жизненная форма, онтогенез, модусы морфологической эволюции

Биоморфология - одна из относительно молодых и наиболее востребованных в настоящее время биологических наук, связанных с описанием и выяснением структурно-функциональных особенностей растений. Она возникла на основе представлений немецкого ученого Е. Варминга о внешнем облике (габитусе) растений, названного им жизненной формой (Wuchsform, Growth-form, growth-habit (нем.), life-form (англ), type biologique (франц.). Но развитие и становление её как самостоятельной области биологического знания связано с исследованиями российских ботаников, прежде всего, И.Г. и Т.И. Серебряковых, их учеников (Л.Е. Гатцук, Л.М. Шафранова и др.) и последователей. Поэтому вполне справедливо считать биоморфологию, как науку, российским феноменом.

Объект исследования биоморфологии - жизненная форма (ЖФ). И.Г. Серебряков (Serebryakov, 1962) определил её как внешний облик - габитус растения, обусловленный своеобразием его системы подземных и надземных вегетативных органов, формирующийся в онтогенезе в результате роста и развития в определенных условиях среды. Позднее он дал краткое ёмкое и лаконичное определение:

\footnotetext{
${ }^{1}$ В данном сообщении из-за ограниченности объёма публикации мы не сможем упомянуть многие работы, поэтому отсылаем читателя к обобщающим изданиям о биоморфологии (Shafranova et al., 2009; Savinykh, Cheryomushkina, 2015) и полному списку публикаций по биоморфологии в России по 2010 г. (Bezdeleva, 2010).
}

ЖФ - габитус растения, связанный с ритмом развития и приспособленный к прошлым и настоящим условиям среды.

Развивая идеи Е. Варминга, Иван Григорьевич указывал не только на статический (структурный) аспект ЖФ, но и динамический (итог и внешнее выражение процессов жизнедеятельности растения в определенных условиях среды; результат эволюционного воздействия и взаимодействия), отмечая, что ЖФ - явление также и эколого-фитоценотическое, поскольку особенности структурной организации и формирования в онтогенезе отражают поведение растений в фитоценозе: способы перемещения в пространстве, взаимодействие с другими организмами, поддержание численности - освоение среды и участие в жизни фитоценоза. Поэтому в сходных условиях среды формируются сходные ЖФ у растений разных систематических групп. Форма жизни растения не одинакова в течение онтогенеза, особенно в связи с расселением и размножением. В связи с этим в настоящее время определены три категории биоморф (Khokhryakov, 1981): основная (габитус растения в зрелом генеративном онтогенетическом состоянии), расселительная (семена и разнообразные диаспоры при вегетативном размножении) и гаметическая (гаметы, гаметофиты). 
И.Г. Серебряков называл учение о ЖФ экологической морфологией. Биологическая составляющая этой науки была значима с самых первых работ в этом направлении, поэтому А.П. Хохряков (Khokhryakov, 1975), поддержав термин Б.М. Козо-Полянского, предложил считать понятия «ЖФ» синонимом «биоморфы», «экологическая морфология» - «биоморфологии». Он определил биоморфологию как учение о биоморфах, их строении, развитии в онтогенезе, распространении, экологии и эволюции.

В отличие от других ботанических наук о внешнем строении растений биоморфологический анализ не заканчивается простым описанием их наружного или внутреннего устройства в зависимости от окружающих условий; биоморфология не сводится только к их классификации, а представляет собой довольно разветвленную науку, в основе которой находится, прежде всего, описание, исследование строения биоморф (жизненных форм), их конструкции, поведения (биология, включая смены фенологических фаз), онтогенетического развития и филогенеза (Маzurenko, Khokhryakov, 2010). Исследования жизненных форм в настоящее время направлены на понимание структуры растения, определяемой его взаимодействиями с внешней средой, выяснение особенностей и логически возможных путей индивидуального развития и онтоморфогенеза растений разных жизненных форм, механизмов, обеспечивающих эти процессы и эволюционные изменения габитуса, характеристики ЖФ и их классификации. Это - основная идея, стратегия действий для понимания, осознания и интерпретации специфики жизни и эволюции растений во всех её проявлениях. В связи с предметом изучения выделяются следующие направления биоморфологических исследований: структурное, онтогенетическое, экологическое, географическое, эволюционное. Основополагающими инструментами для их реализации являются разработанные российскими ботаниками концепции к изучению ЖФ и интерпретации полученных данных.

Изучение структурной организации основано на познании закономерно повторяющихся в ходе индивидуального развития элементов особи в результате циклического морфогенеза (Marfenin, 1999). Главный принцип анализа ЖФ со времени И.Г. Серебрякова - системный анализ: выделение в теле растения повторяющихся структурно-биологических единиц, выявление их взаимосвязи и размещения на шкале биологического времени. У древесных растений - это скелетная ось, парциальный куст (Serebryakov, 1962), система побега формирования, система побега ветвления, составная скелетная ось (Mazurenko, Khokhryakov, 1977), элементарная побеговая система (Antonova, Lagunova, 1999). У трав с симподиальным нарастанием - монокарпический побег, образующийся обычно из пазушной почки на многолетней части растения, растущий в течение одного, двух или нескольких лет, завершающий развитие образованием цветка или соцветия, с сохранением в течение разного времени базального участка в составе побеговой системы. Это специализированный побег с выраженными структурно-функциональными зонами (Troll, 1964; Borisova, Popova, 1990). Общий спектр их у ортотропных и анизотропных побегов выражается сочетанием следующих зон: нижняя (Musina, 1976), средняя, верхняя (Borisova, Popova, 1990) и интеркалярная (Astashenkov, 2015) торможения, возобновления, обогащения, главное соцветие. Такой монокарпический побег обладает в высшей степени автономностью и независимостью от остальной части тела растения.

У трав с моноподиальным или гемисимподиальным нарастанием побеговых систем спектр структурно-функциональных зон другой: здесь последовательно чередуются зоны вегетативная, вегетативно-генеративная и вторичного вегетативного нарастания (Serebryakova, Petukhova, 1978; Savinykh, 2006). При отсутствии выраженной зоны возобновления ветвление у этих растений рассеянное.

В последнее время в связи с осознанием растения как модульного организма предложено для характеристики его структуры несколько систем иерархически соподчиненных единиц: элементарный метамер (Barykina, Gulenkova, 1983), 12 единиц Л.Е. Гатцук (Gatsuk, 2008), три категории модулей Н.П. Савиных (Savinykh, 2008; Savinykh, Maltseva, 2008), повторяющаяся архитектурная единица (Bartelemy, 2007). Т.В. Кузнецова (Kuznetsova, 1995) определила требования к таким структурным единицам: их можно легко находить у растения, различать и мысленно проводить границы между ними; отчетливо представлять, с какой целью эти единицы выделяются. Но очевидно одно: использование системного подхода к описанию структуры растения позволяет не только описать её с позиций определенной идеологии, но и учитывать биологическое время при характеристике ЖФ, о чём также писал И.Г. Серебряков.

Общую конструкцию и принципы её построения у растений определяют, прежде всего, наследственныесвойстваорганизма, а конкретные условия среды вносят в них известные корректировки, что в целом и создаёт внешний вид, габитус растения. В последнее время появилось много примеров 
поливариантности развития растений разных типов (Zhukova, 2008; Voskresenskaya, 2006; Astashenkov, 2015; Kyznetsova, 2015; Cheryomushkina, Guseva, 2015; и др.). Структурная поливариантность, как и поливариантность онтогенеза, является следствием модульной организации растений (Savinykh, 2006).

Изучение становления ЖФ в динамике, как смену габитуса в онтогенезе, позволило описать два этапа и 16 возможных фаз морфогенеза в индивидуальном развитии растений (Smirnova et al., 1976; Savinykh, Cheryomushkina, 2015). На первых этапах анализа морфогенеза фаза морфогенеза рассматривалась как структура особи на определённой стадии её развития - онтобиоморфа, как особая ЖФ в смысле А.П. Хохрякова (Khokhryakov, 1978). Позднее фазу морфогенеза стали рассматривать как процесс перехода особи в новое качественное состояние, определяемый способами нарастания, кущения, морфологической дезинтеграцией и накоплением растением в результате этого определенных изменений, обеспечивающих появление новой фазы морфогенеза как новой структуры. Познание хода онтоморфогенеза у растений с разными ЖФ позволяет выяснить механизмы преобразований габитуса растений и логически возможные пути этих изменений. Это важно для выяснения модусов морфологической трансформации ЖФ в ходе эволюции, в прикладных исследованиях для оценки состояния редких и охраняемых видов растений в конкретных условиях среды, разработки программ их сохранения.

Особое место в изучении ЖФ в динамике представляет собой учение об архитектурных моделях и моделях побегообразования, как видимом выражении генетической программы развития растения, проявляющемся во взаимном расположении модулей (побегов) в пределах общей конструкции взрослого растения (Halle, Oldeman, 1970), как наследственно закрепленном типе формирования побеговой системы растения, определяемом, в первую очередь, особенностями функционирования верхушечной и интеркалярной меристем и типом ветвления (Serebryakova, 1977; и др.). ЖФ, как продукт реализации модели, несет отпечаток адаптации растения к внешним условиям. Архитектурная модель и модель побегообразования, по мнению Т.И. Серебряковой (Serebryakova, 1985), есть лишь форма роста, в отличие от ЖФ, которая есть способ жизни.

Динамический аспект анализа ЖФ предполагает также учёт гетерохронии - разновременного развития органов и их систем и гетеротопий разных структур, образующихся на основе однотипных элементов (Savinykh, 2015). Особенно это относится к пазушным почкам и их производным.
Именно гетерохронией и гетеротопией объясняется появление побегов формирования и дополнения у древесных растений, силлептических побегов в зоне обогащения у трав, итеративное ветвление у водных и прибрежно-водных растений.

ЖФ отражают приспособления не только к настоящим, но и прошлым условиям среды. Сравнительно-морфологический анализ растений с позиций статики и динамики позволяют определить особенности растительной формы жизни и модусы морфологической эволюции ЖФ (Serebryakova, 1983). Растения не способны, как животные, к значительным изменениям на эмбриональной стадии развития, онтогенез и морфогенез у них идут параллельно и влияют друг на друга, габитус меняется от начала прорастания семени до отмирания или морфологической дезинтеграции особи. Наибольшее влияние на изменение ЖФ имеют преобразования побегов как структурных элементов особи, и изменения целостных растений. По аналогии с представлениями А.Н. Северцова (Severtsov, 1939) о филэмбриогенезах, Т.И. Серебрякова (Serebryakova, 1983) определила модусы морфологической эволюции ЖФ растений: терминальные, медиальные и базальные пролонгации, девиации и аббревиации в онтогенезе побега и целостной особи, их роль в трансформации биоморф.

Многочисленные исследования последователей И.Г. Серебрякова показали многообразие путей происхождения трав от древесных растений в разных таксонах, относительное сходство конечного результата, параллельные ряды изменений ЖФ, обусловленные закономерной изменчивостью их побегов, побеговых и корневых систем. Эти ряды подобны гомологическим рядам наследственной изменчивости, описанным Н.И. Вавиловым, и подтверждают предположение И.Г. Серебрякова (Serebryakov, 1962: 118-119) об «эволюционной системе биоморф как системе параллельных рядов ЖФ, своеобразно и с различной полнотой повторяющих все этапные формы от деревьев до травянистых многолетников».

В настоящее время для характеристики ЖФ используется большое число признаков: число цветений, длительность жизни надземных осей, листьев, особи в целом, тип подземных органов у трав, время и способ морфологической дезинтеграции, способ воздействия растения на среду, биологический тип по С. Раункиеру, тип побегов (особенно у трав) и модель побегообразования. Такие характеристики ЖФ обеспечивают качественное и разностороннее сравнение их на разных уровнях системной организации особей: отдельных побегов и их структурно- фун- 
кциональных зон, структурных элементов, последовательное чередование которых определяет тип биоморфы - основного модуля, в нашем понимании (Savinykh, 2008; Savinykh, Maltseva, 2008), целостных особей.

Классификация ЖФ по максимально возможному числу признаков позволяет строить принципиально новые системы ЖФ. Особенно это плодотворно для отдельных крупных таксонов покрытосеменных: семейства - Poaceae (Serebryakova, 1971), Saxifragaceae (Zhmylev, 2004), Ranunculaceae (Barykina, 1995), подсемейство Sedoideae, Crassulaceae (Goncharova, 2006), роды Allium (Cheryomushkina, 2004), Veronica (Savinykh, 2006), Agrostis (Kurchenko, 2010), Salvia (Baikova, 1996) и др., и споровые растения (Shorina, 1994; Derzhavina, 2006). Эти системы и классификации, без сомнения, являются эволюционными.

Таким образом, основными концепциями в современной биоморфологии являются системный подход при анализе ЖФ, представления о растении как модульном организме с меняющимся габитусом в течение всей жизни, фазе морфогенеза как процессе и результате, циклическом морфогенезе как основе формирования тела растения, двойственности ЖФ, обусловленной генетически запрограммированной основой формообразования и возникающими на этом фундаменте модификациями. На основе их развиваются структурное, онтогенетическое, экологическое, географическое, эволюционное направления биоморфологии.

Сегодня мы можем констатировать, что предположение И.Г. Серебрякова о том, что в ближайшие десятилетия (после 1962 г.) дадут многое для понимания эволюции ЖФ, ознаменовав новую эпоху в учении о ЖФ растений, было не безосновательным.

Исследование выполнено при финансовой поддержке РФФИ в рамках научных проектов № 15-04-02857-a, № 16-04-01073

\section{Список литературы}

[Antonova, Lagunova] Антонова И.С., Лагунова Н.Г. 1999. О модульной организации некоторых групп высших растений. Журн. Общ. биологии. Т. 60. №1. C. 49-59.

[Astashenkov] Асташенков А.Ю. 2015. Морфологическая адаптация Nepeta pamirensis Franch. (Lamiaceaе) к условиям высокогорного Памира. Сибирский экологический журнал. Т. 22. №5. C. 770-784. DOI: 10.15372/SEJ20150510

[Baikova] Байкова Е.В. 1996. Биоморфология шалфеев при интродукции в Западной Сибири. Новосибирск. 116 с.
Barthelemy D., Caraglio Y. 2007. Plant architecture: a dynamic, multilevel and comprehensive approach to plant form, structure and ontogeny. Ann. Bot. 99(3): 375-407. https://doi.org/10.1093/aob/mcl260

[Barykina] Барыкина Р.П. 1995. Поливариантность способов вегетативного размножения и расселения в сем. Ranunculaceae. Бюл. МОИП. Отд. биол. T. 100. №1. C. 53-65.

[Barykina, Gulenkova] Барыкина Р.П., Гуленкова М.А. 1983. Элементарный метамер побега цветкового растения. Бюл. МОИП. Отд. биол. Т. 88. №4. C. $114-124$.

[Bezdeleva] Безделева Т.А. (ред.). 2012. Экологическая морфология сосудистых растений: библиограф. указ. лит. на рус. яз. (с начала XX в. по 2010 г.). Владивосток. $512 \mathrm{c.}$

[Borisova, Рopova] Борисова И.В., Попова Г.А. 1990. Разнообразие функционально-зональной структуры побегов многолетних трав. Бот. журн. Т. 75. №10. С. 1420-1426.

[Cheryomushkina, Guseva] Черёмушкина B.A., Гусева A.A. 2015. Жизненные формы Scutellaria supina L. (Lamiaceae). Сибирский экологический журнал. T. 22. №5. C. 756-769.

[Cheryomushkina] Черемушкина В.A. 2004. Биоморфология луков Евразии. Новосибирск. 280 с.

[Derzhavina] Державина Н.M. 2006. Биоморфология и анатомия равноспоровых папоротников (эпилитов, эпифитов, земноводных и водных) в связи с адаптациогенезом: автореф. дис.... д-ра биол. наук. М. 50 с.

[Gatsuk] Гатцук Л.Е. 2008. Растительный организм: опыт построения иерархической системы его структурно-биологических единиц. В сб.: Современные подходы к описанию структуры растений. Киров. С. 29-41.

[Goncharova] Гончарова С.Б. 2006. Очитковые (Sedoideae, Crassulaceae) флоры российского Дальнего Востока. Владивосток. 223 с.

Halle F., Oldeman R.A.A. 1970. Essai sur l' architecture et la dynamique de crossiance des arbres tropicaux. Paris. 178 p.

[Khokhryakov] Хохряков А.П. 1975. Соматическая эволюция однодольных. М. 196 с.

[Khokhryakov] Хохряков А.П. 1978. Изменения образа жизни растений в онтогенезе. Журн. Общ. Биологии. T. 39. №3. C. 357-372.

[Khokhryakov] Хохряков А.П. 1981.Категории жизненных форм у растений и их эволюция. Журн. Общ. Биологии. Т. 42. №2. С. 169-180.

[Kurchenko] Курченко Е.И. 2010. Род полевица (Agrostis L., сем. Роасеае) России и сопредельных стран. M. $516 \mathrm{c}$.

[Kuznetsova] Кузнецова С.Б. 2015. Биоморфология кустарниковой лианы Atragene sibirica L. Сибирский экологический журнал. Т. 22. №5. С. 725-734. DOI: 10.15372/SEJ20150506

[Kuznetsova] Кузнецова Т.В. 1995. К истории развития представлений о плане строения побега сосудистых растений и о месте филлома в нем. Бот. журн. Т. 80. №7. C. 1-11. 
[Marfenin] Марфенин Н.Н. 1999. Концепция модульной организации в развитии. Журн. Общ. биол. Т. 60. №1. C. 6-17.

[Mazurenko, Khokhryakov] Мазуренко М.Т., Хохряков А.П. 1977. Структура и морфогенез кустарников. M. 159 c.

[Mazurenko, Khokhryakov] Мазуренко М.Т., Хохряков А.П. 2010. Некоторые понятия биоморфологии. Бюлл. БСИ ДВО РАН. [Электронный ресурс]: науч. журн. Владивосток. Вып. 5. С. 106-116. http://botsad. $\mathrm{ru} / \mathrm{media} /$ oldfiles/journal/number5/18.pdf

[Musina] Мусина Л.С. 1976. Побегообразование и становление жизненных форм некоторых розеткообразующих трав. Бюл. МОИП. Отд. биол. T. 81. №6. C. 123-132.

[Savinykh] Савиных Н.П. 1979. Побегообразование и взаимоотношения жизненных форм в секции Veronica рода Veronica. Бюлл. МОИП. Отд. биол. Т. 84. №3. C. 92-105.

[Savinykh] Савиных Н.П. 2006. Род вероника: морфология и эволюция жизненных форм. Киров. 324 с.

[Savinykh] Савиных Н.П. 2008. Применение концепции модульной организации к описанию структуры растения. В сб.: Современные подходы к описанию структуры растений. Киров. С. 47-69.

Savinykh N.P. 2015. Modular as a Basis of Heterochronies and Heterotopies in Flowering Plants. Paleontogical Journal. 49(14): 1-10. https://doi.org/10.1134/ S0031030115140166

[Savinykh, Cheryomushkina] Савиных Н.П., Черёмушкина В.А. 2015. Биоморфология: современное состояние и перспективы. Сибирский экологический журнал. Т. 22. №5. С. 659-670. DOI: 10.15372/SEJ20150501

[Savinykh, Maaltseva] Савиных Н.П., Мальцева Т.А. 2008. Модуль у растений как структура и категория. Вестн. Тверского гос. ун-та. Сер. Биол. и экол. №9. C. $227-234$.

[Serebryakov] Серебряков И.Г. 1962. Экологическая морфология растений. М. 378 с.
[Serebryakova] Серебрякова Т.И. 1977. Об основных «архитектурных моделях» травянистых многолетников и модусах их преобразований. Бюлл. МОИП. Отд. биол. Т. 82. №2. С. 112-128.

[Serebryakova] Серебрякова Т.И. 1983. О некоторых модусах морфологической эволюции цветковых растений. Журн. общ. биол. Т. 44. №5. С. 579-593.

[Serebryakova] Серебрякова Т.И. 1985. Деякі актуальні проблеми екологічної морфології рослин. Українский ботанічний журнал. 42(1): 1-8.

[Serebryakova, Petukhova] Серебрякова Т.И., Петухова Л.В. 1978. Архитектурная модель и жизненные формы некоторых розоцветных. Бюлл. МОИП. Отд. биол. Т. 83. №6. С. 51-66.

[Severtsov] Северцов А.Н. 1939. Морфологические закономерности эволюции. М.-Л. 610 с.

[Shafranova] Шафранова Л.М., Гатцук Л.Е., Шорина Н.И. 2009. Биоморфология растении и её влияние на развитие экологии. М. $86 \mathrm{c}$.

[Shorina]Шорина Н.И. 1994. Экологическая морфология и популяционная биология представителей подкласса Polypodiidae: Автореф. дисс....докт. биол .наук. М. 34 с.

[Smirnova] Смирнова О.В., Заугольнова Л.Б., Ермакова И.М. и др. 1976. Ценопопуляции растений (основные понятия и структура). М. 216 с.

Troll W. 1964. Die Infloreszenzen. B. 1. Jena. 615 s.

[Voskresenskaya] Воскресенская О.Л. (ред.). 2006. Поливариантность развития организмов, популяций и сообществ: науч. издание. Йошкар-Ола. 326 с.

[Zhmylev] Жмылев П.Ю. 2004. Род Saxifraga L. (Saxifragaceae): биоморфология, систематика и эволюция жизненных форм: дис. ... д-ра биол. наук. М. 416 с.

[Zhukova] Жукова Л.А. 1995. Популяционная жизнь луговых растений. Йошкар-Ола. 224 с.

[Zhukova] Жукова Л.А. 2008. Поливариантность развития организмов в разных царствах биосферы. В сб.: Современные подходы к описанию структуры растения. Киров. С. 240-260. 


\title{
Main directions and concepts of biomorphology in Russia
}

\author{
(C) N.P. Savinykh ${ }^{1}$, V.A. Cheryomushkina ${ }^{2}$ \\ ${ }^{1}$ Vyatka State University, Kirov, Russia \\ e-mail:savva_09@mail.ru \\ ${ }^{2}$ The Central Siberian Botanical Garden of the SB RAS, Novosibirsk, Russia \\ e-mail: cher.51@mail.ru
}

\begin{abstract}
Based on the analysis of long-term biomorphological studies of different plant groups, the main directions (structural, ontogenetic, ecological, geographical, evolutionary) and main concepts (system approach in the analysis of life forms; the concept of the plant as a modular organism with a changing habit throughout life; morphogenesis phase as a process and result; cyclic morphogenesis as the basis for the formation of the body of the plant; the duality of life forms due to the genetically programmed basis of morphogenesis and the modifications arising on this foundation) of this modern science are noted.
\end{abstract}

Keywords: biomorphology, structural organization, ontomorphogenesis, modular organization, life form, ontogeny, modes of morphological evolution

\section{Refere n c es}

Antonova I.S., Lagunova N.G. 1999. O modulnoi organizatsii nekotorykh grupp vysshikh rastenii. [On the modular organization of some groups of higher plants]. Zhurnal obshchei biologii. 60(1): 49-59. (In Russ.)

Astashenkov A.Yu. 2015. Morfologicheskaya adaptatsiya Nepeta pamirensis Franch. (Lamiaceae) k usloviyam vysokogornogo Pamira [Morphological adaptation of Nepeta pamirensis Franch. (Lamiaceae) to the conditions of the Pamir Mountains]. Sibirskii ekologicheskii zhurnal. 22(5): 770-784. (In Russ.) DOI: 10.15372/ SEJ20150510

Baikova E.V. 1996. Biomorfologiya shalfeev pri introduktsii v Zapadnoi Sibiri [Biomorphology of Salvia during introduction in Western Siberia]. Novosibirsk. 116 pp. (In Russ.)

Barthelemy D., Caraglio Y. 2007. Plant architecture: a dynamic, multilevel and comprehensive approach to plant form, structure and ontogeny. Ann. Bot. 99(3): 375-407. https://doi.org/10.1093/aob/mcl260

Barykina R.P. 1995. Polivariantnost sposobov vegetativnogo razmnozheniya $\mathrm{i}$ rasseleniya $\mathrm{V}$ sem. Ranunculaceae [The polyvariance of the methods of vegetative reproduction and settling in the family Ranunculaceae]. Byull. MOIP. Otd. Biol. [Bulletin of Moscow Society of Naturalists. Biological series]. 100(1): 53-65. (In Russ.)

Barykina R.P., Gulenkova M.A. 1983. Elementarnyi metamer pobega tsvetkovogo rasteniya [Elementary metamer shoot of a flowering plant]. Byull. MOIP. Otd. Biol. [Bulletin of Moscow Society of Naturalists. Biological series]. 88(4): 114-124. (In Russ.)

Bezdeleva T.A. (ed.). 2012. Ekologicheskaya morfologiya sosudistykh rastenii: bibliograficheskii ukazatel literatury na russkom yazyke (s nachala 20 veka po 2010 g.) [Ecological morphology of vascular plants: a bibliographic index of literature in Russian (from the beginning of the twentieth century to 2010)]. Vladivostok. 512 pp. (In Russ.)

Borisova I.V., Popova G.A. 1990. Raznoobraziye funktsionalno-zonalnoi struktury pobegov mnogoletnikh trav [Diversity of functional-zonal structure of shoots of perennial herbs]. Botanicheskii Zhurnal. 75(10): 14201426. (In Russ.)
Cheryomushkina V.A., Guseva A.A. 2015. Zhiznennyye formy Scutellaria supina L. (Lamiaceae) [Life forms of Scutellaria supina L. (Lamiaceae)]. Sibirskii ekologicheskii zhurnal. 22(5): 756-769. (In Russ.) DOI: 10.15372/SEJ20150509

Cheryomushkina V.A. 2004. Biomorfologiya lukov Evrazii [Onion biomorphology in Eurasia]. Novosibirsk. 280 pp. (In Russ.)

Derzhavina N.M. 2006. Biomorfologiya $i$ anatomiya ravnosporovykh paporotnikov (epilitov, epifitov, zemnovodnykh $i$ vodnykh) $v$ svyazi $s$ adaptatsiogenezom: avtoreferat diss. ... dokt. boil. nauk [Biomorphology and anatomy of equisporous ferns (epiliths, epiphytes, amphibians and aquatic) in connection with adaptatiogenesis: abstract of the Dr. boil. sci. diss.]. Moscow. 50 pp. (In Russ.)

Gatsuk L.E. 2008. Rastitelnyi organism: opyt postroeniya ierarkhicheskoi sistemy ego strukturno-biologicheskikh edinits [Plant organism: the experience of constructing a hierarchical system of its structural-biological units]. In: Sovremennyye podkhody $k$ opisaniyu struktury rastenii [Modern approaches to the description of the structure of plants]. Kirov. 29-41 pp. (In Russ.)

Goncharova S.B. 2006. Ochitkovyye (Sedoideae, Crassulaceae) flory rossiiskogo dalnego Vostoka [Sedoideae (Crassulaceae) of the flora of the Russian Far East]. Vladivostok. 223 pp. (In Russ.)

Halle F., Oldeman R.A.A. 1970. Essai sur l' architecture et la dynamique de crossiance des arbres tropicaux. Paris. $178 \mathrm{pp}$.

Khokhryakov A.P. 1975. Somaticheskaya evolyutsiya odnodolnykh [Somatic evolution of Monocots]. Moscow. 196 pp. (In Russ.)

Khokhryakov A.P. 1978. Izmeneniya obraza zhizni rastenii $\mathrm{v}$ ontogeneze [Changes in the way of plant life in ontogeny]. Zhurnal obshchei biologii. 39(3): 357-372. (In Russ.)

Khokhryakov A.P. 1981. Kategorii zhiznennykh form u rasteniii ikh evolutsiya [Categories of life forms of plants and their evolution]. Zhurnal obshchei biologii. 42(2): 169-180. (In Russ.) 
Kurchenko E.I. 2010. Rod polevitsa (Agrostis L., сем. Poaceae) Rossi ii sopredelnykh stran [Genus Agrostis L. (Poaceae) of Russia and Neighboring Countries]. Moscow. 516 pp. (In Russ.)

Kuznetsova S.B. 2015. Biomorfologiya kustarnikovoi liany Atragene sibirica L. [Biomorphology of shrub liana Atragene sibirica L.]. Sibirskii ekologicheskii zhurnal. 22(5): 725-734. (In Russ.) DOI: 10.15372/SEJ20150506

Kuznetsova T.V. 1995. K istorii razvitiya predstavlenii o plane stroyeniya pobega sosudistykh rastenii i o meste filloma $\mathrm{v}$ nem [To the history of the development of ideas about the structure of vascular plants shoot and the place of the phyllom in it]. Botanicheskii Zhurnal. 80(7): 1-11. (In Russ.)

Marfenin N.N. 1999. Kontseptsiya modulnoi organizatsii $\mathrm{v}$ razvitii [The concept of modular organization in development]. Zhurnal obshchei biologii. 60(1): 6-17. (In Russ.)

Mazurenko M.T., Khokhryakov A.P. 1977. Struktura $i$ morfogenez kustarnikov [Structure and morphogenesis of shrubs]. Moscow. 159 pp. (In Russ.)

Mazurenko M.T., Khokhryakov A.P. 2010. Nekotoryye ponyatiya biomorfologii [Some concepts of biomorphology]. Byull. BSI DVO RAN [Bulletin of the BGI FEB RAS]. 5: 106-116. (In Russ.) Available at: http://botsad.ru/media/oldfiles/journal/number5/18.pdf

Musina L.S. 1976. Pobegoobrazovaniye i stanovleniye zhiznennykh form nekotorykh rozetkoobrazuyushchikh trav [Shoot formation and developing of life forms of some rosette-forming herbs]. Byull. MOIP. Otd. Biol. [Bulletin of Moscow Society of Naturalists. Biological series]. 81(6): 123-132. (In Russ.)

Savinykh N.P. 1979. Pobegoobrazovaniye i vzaimootnosheniya zhiznennykh form v sektsii Veronica roda Veronica [Shoot formation and relationships of life forms in the section Veronica genus Veronica]. Byull. MOIP. Otd. Biol. [Bulletin of Moscow Society of Naturalists. Biological series]. 84(3): 92-105. (In Russ.)

Savinykh N.P. 2006. Rod veronica: morfologiya i evolyutsiya zhiznennykh form [The genus Veronica: morphology and evolution of life forms]. Kirov. 324 pp. (In Russ.)

Savinykh N.P. 2008. Primeneniye kontseptsii modulnoi organizatsii k opisaniyu struktury rasteniya [Application of the concept of modular organization to the description of the structure of the plant] Применение концепции модульной организации к описанию структуры растения. In: Sovremennyye podkhody $k$ opisaniyu struktury rastenii [Modern approaches to the description of the structure of plants]. Kirov. 47-69 pp. (In Russ.)

Savinykh N.P. 2015. Modular as a Basis of Heterochronies and Heterotopies in Flowering Plants. Paleontogical Journal. 49(14): 1-10. https://doi.org/10.1134/ S0031030115140166

Savinykh N.P., Cheryomushkina V.A. 2015. Biomorfologiya: sovremennoye sostoyaniye i perspektivy [Biomorphology: current state and prospects]. Sibirskii ekologicheskii zhurnal. 22(5): 659-670. (In Russ.) DOI: 10.15372/SEJ20150501

Savinykh N.P., Maltseva T.A. 2008. Modul u rastenii kak struktura i kategoriya [Module in plants as structure and category]. Vestnik Tverskogo gosudarstvennogo universiteta. Seriya biologiya i ekologiya [Herald of TVGU. Series: Biology and Ecology]. 9: 227-234.
Serebryakov I.G. 1962. Ekologicheskaya morfologiya rastenii [Ecological morphology of plants]. Moscow. 378 pp. (In Russ.)

Serebryakova T.I. 1977. Ob osnovnykh arkhitekturnykh modelyakh travyanistykh mnogoletnikov i modusakh ikh preobrazovanii [On the main "architectural models" of herbaceous perennials and the modes of their transformation]. Byull. MOIP. Otd. Biol. [Bulletin of Moscow Society of Naturalists. Biological series]. 82(2): 112-128. (In Russ.)

Serebryakova T.I. 1983. O nekotorykh modusakh morfologicheskoi evolyutsii tsvetkovykh rastenii [On some modes of the morphological evolution of flowering plants]. Zhurnal obshchei biologii. 44(5): 579-593. (In Russ.)

Serebryakova T.I. 1985. Деякі актуальні проблеми екологічної̈ морфологї̈ рослин. Українский ботанічний журнал. 42(1): 1-8. (In Ukrainian)

Serebryakova T.I., Petukhova L.V. 1978. Arkhitekturnaya model i zhiznennyye formy nekotorykh rozotsetnykh [The architectural model and life forms of some Rosaceae]. Byull. MOIP. Otd. Biol. [Bulletin of Moscow Society of Naturalists. Biological series]. 83(6): 51-66. (In Russ.)

Severtsov A.N. 1939. Morfologicheskiye zakonomernosti evolutsii [Morphological patterns of evolution]. Moscow-Leningrad. 610 pp. (In Russ.)

Shafranova L.M., Gatsuk L.E., Shorina N.I. 2009. Biomorfologiya rastenii i ee vliyaniye na razvitiye ekologii [Biomorphology of the plant and its influence on the development of ecology]. Moscow. 86 pp. (In Russ.)

Shorina N.I. 1994. Ekologicheskaya morfologiya i populyatsionnaya biologiya predstavitelei podklassa Polypodiidae: avtoreferat diss. ... dokt. boil. nauk [Ecological morphology and population biology of representatives of the subclass Polypodiidae: abstract of the Dr. boil. sci. diss.]. Moscow. 34 pp. (In Russ.)

Smirnova O.V., Zaugolnova L.B., Ermakova I.M. et al. 1976. Tsenopopulyatsii rastenii (osnovnyye ponyatiya $i$ struktura) [Coenopopulation of plants (basic concepts and structure)]. Moscow. 216 pp. (In Russ.)

Troll W. 1964. Die Infloreszenzen. B. 1. Jena. 615 s.

Voskresenskaya O.L. (ed.). 2006. Polivariantnost razvitiya organizmov, populyatsii i soobshchestv: nauchnoye izdaniye [Polyvariant development of organisms, populations and communities: scientific edition]. Yoshkar-Ola. 326 pp. (In Russ.)

Zhmylev P.Yu. 2004. Rod Saxifraga L. (Saxifragaceae): biomorfologiya, sistematika i evolyutsiya zhiznenny$k h$ form: diss. ... dokt. boil. nauk [Genus Saxifraga L. (Saxifragaceae): biomorphology, systematics and evolution of life forms: Dr. boil. sci. diss.]. Moscow. 416 pp. (In Russ.)

Zhukova L.A. 1995. Populyatsionnaya zhizn lugovykh rastenii [Population life of meadow plants]. Yoshkar-Ola. 224 pp. (In Russ.)

Zhukova L.A. 2008. Polivariantnost razvitiya organizmov $\mathrm{v}$ raznykh tsarstvakh biosfery [Polyvariant development of organisms in different kingdoms of the biosphere]. In: Sovremennyye podkhody k opisaniyu struktury rastenii [Modern approaches to the description of the structure of plants]. Kirov. 240-260 pp. (In Russ.) 